\title{
2D-Perfusion Angiography Using Carbon Dioxide (CO2): A Feasible Tool to Monitor Immediate Treatment Response to Endovascular Therapy of Peripheral Arterial Disease?
}

\author{
Cornelia L. A. Dewald ${ }^{1}$ Lena S. Becker ${ }^{1} \cdot$ Sabine K. Maschke $^{1} \cdot$ Timo C. Meine $^{1}$ • \\ Bernhard C. Meyer $^{1} \cdot$ Frank K. Wacker ${ }^{1} \cdot$ Jan B. Hinrichs $^{1}$ (D)
}

Received: 16 July 2020/Accepted: 19 November 2020/Published online: 16 December 2020

(C) The Author(s) 2020

\begin{abstract}
Purpose Patients with peripheral arterial disease (PAD) or critical limb ischemia (CLI) require revascularization. Traditionally, endovascular therapy (EVT) is performed with iodinated contrast agent (ICM), which can provoke potential deterioration in renal function. $\mathrm{CO} 2$ is a safe negative contrast agent to guide vascular procedures, but interpretation of $\mathrm{CO} 2$ angiography is challenging. Changes in blood flow following iodine-aided EVT are assessable with 2D-perfusion angiography (2D-PA). The aim of this study was to evaluate 2D-PA as a tool to monitor blood flow changes during $\mathrm{CO}_{2}$-aided EVT.

Material and Methods 2D-PA was performed before and after ten EVTs (nine stents; one endoprosthesis; 10/2012-02/2020) in nine patients (six men; $65 \pm 10 y$ ) with Fontaine stage $\operatorname{IIb}(n=8)$ and IV $(n=1)$. A reference
\end{abstract}

Jan B. Hinrichs

Hinrichs.jan@mh-hannover.de

Cornelia L. A. Dewald

dewald.cornelia@mh-hannover.de

Lena S. Becker

becker.lena@mh-hannover.de

Sabine K. Maschke

maschke.sabine@mh-hannover.de

Timo C. Meine

meine.timo@mh-hannover.de

Bernhard C. Meyer

meyer.bernhard@mh-hannover.de

Frank K. Wacker

wacker.frank@mh-hannover.de

1 Institute for Diagnostic and Interventional Radiology,

Hannover Medical School, Carl-Neuberg-Str. 1, 30625

Hannover, Germany

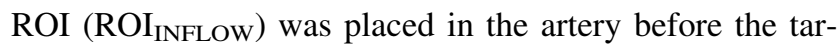

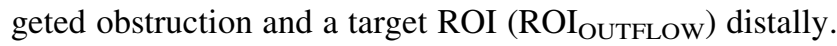
Corresponding ROIs were used pre- and post-EVT. Time to peak (TTP), peak density (PD) and area under the curve (AUC) were computed. The reference/target ROI ratios

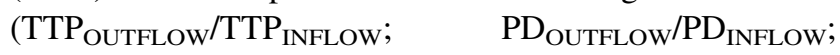
$\mathrm{AUC}_{\text {OUTFLOW }} / \mathrm{AUC}_{\text {INFLOW }}$ ) were calculated.

Results 2D-PA was technically feasible in all cases. A significant increase of $82 \%$ in $\mathrm{PD}_{\text {OUTFLOW }} / \mathrm{PD}_{\text {INFLOW }}$ $(0.44 \pm 0.4$ to $0.8 \pm 0.63 ; p=0.002)$ and of $132 \%$ in AUC $_{\text {OUTFLOW }} / \mathrm{AUC}_{\text {INFLOW }}(0.34 \pm 0.22$ to $0.79 \pm 0.59$; $p=0.002$ ) was seen. A trend for a decrease in TTP $_{\text {OUTFLOW }} /$ TTP $_{\text {INFLOW }}$ was observed $(-24 \%$; $5.57 \pm 3.66 \mathrm{~s}-4.25 \pm 1.64 \mathrm{~s} ; p=0.6$ ).

Conclusion The presented 2D-PA technique facilitates the assessment of arterial flow in CO2-aided EVTs and has the potential to simplify the assessment of immediate treatment response.

Keywords 2D-perfusion angiography · Carbon dioxide $\cdot$ Negative contrast agent $\cdot$ Endovascular treatment $\cdot$ Stent $\cdot$ Peripheral arterial disease

$\begin{array}{ll}\text { Abbreviations } \\ \text { 2D-PA } & \text { 2D-perfusion angiography } \\ \text { AUC } & \text { Area under the time-density curve } \\ \text { CKD } & \text { Chronic kidney disease } \\ \text { CO2 } & \text { Carbon dioxide } \\ \text { DSA } & \text { Digital subtraction angiography } \\ \text { eGFR } & \text { Estimated glomerular filtration rate } \\ \text { EVT } & \text { Endovascular therapy } \\ \text { ICM } & \text { Iodinated contrast medium } \\ \text { PAD } & \text { Peripheral arterial disease } \\ \text { PD } & \text { Peak density value } \\ \text { ROI } & \text { Region of interest }\end{array}$


TTP

Time to peak

\section{Introduction}

Peripheral arterial disease (PAD) is a major public health problem with rising prevalence and considerable socioeconomic impact [1-3]. Current guidelines recommend an "endovascular first" strategy for stenosed or occluded vessels in patients with claudication and critical limb ischemia, which leads to an increase in endovascular therapy (EVT) [1, 2, 5, 6]. Coexisting renal, diabetic, vascular and other chronic comorbidities are common in patients with PAD, which can complicate disease management $[2,7,8]$. Carbon dioxide (CO2) has long been acknowledged as a safe intravascular, negative contrast agent to guide vascular procedures in patients with chronic kidney disease (CKD), hypersensitivities to iodinated contrast agent (ICM) or hyperthyroidism [1, 4, 9-11]. Nevertheless, $\mathrm{CO} 2$ is reported to be underutilized in the past [12] - mainly due to the discrepancy between $\mathrm{CO} 2$ and ICM regarding application and image analysis. The unsteady image quality in this infrequently used technique can limit the interpretation of contrast flow changes following EVT. This might negatively affect EVT with CO2, as the angiographic endpoint in EVT depends on the visual comparison of blood flow before and after revascularization.

2D-perfusion angiography (2D-PA) is a newly available technique for the assessment of blood flow and tissue perfusion. This technique relies on dedicated post-processing of standard digital subtraction angiography (DSA) images and computes time-density curves, which represent the flow of contrast agent within a region of interest (ROI) throughout the entire DSA run [2,18-22]. Thus, it allows us to assess the perfusion distal to occluded vessels [2, 13-17] before, during and after endovascular revascularization. This might offer an opportunity to predict and evaluate clinical outcomes. 2D-PA used in CO2-guided interventions might increase the diagnostic confidence and thus support the visual interpretation. The aim of this study was to evaluate the feasibility of $2 \mathrm{D}-\mathrm{PA}$ as a tool to monitor perfusion changes after $\mathrm{CO} 2$-aided EVT in patients with PAD.

\section{Material and Methods}

\section{Patient Population}

In total, 857 diagnostic and interventional DSA of the lower extremity, performed at our institution between 10/2014 and 02/2020, were screened for CO2-aided imaging. Out of these, we included all consecutive studies with paired pre- and post-interventional DSA series performed with $\mathrm{CO} 2$. In total, ten interventions in nine patients with PAD admitted for EVT of the pelvic/lower extremity arteries were assessed. Indications for $\mathrm{CO} 2$ as contrast agent were severe CKD with preserved urine excretion in all patients $(n=9 / 9 ; 100 \%)$ and additional allergy to ICM and hyperthyroidism in one patient each $(n=1 / 9 ; 11 \%)$.

\section{Angiography}

The DSA images were acquired using a monoplane, ceiling-mounted angiographic system equipped with a $30 \times 40 \mathrm{~cm}$ flat-panel detector (Artis $\mathrm{Q}^{\circledR}$ or Artis pheno, Siemens Healthcare, Forchheim, Germany). Intra-arterial $\mathrm{CO} 2$ was administered using a dedicated angiography set (CO2-Angioset nach Schmitz-Rode/Alzen, Optimed, Ettlingen, Germany) via transfemoral approach.

For each DSA of the pelvic or the femoral arteries, 60-80 $\mathrm{ml}$ of pure $\mathrm{CO} 2$ was administered with a constant injection pressure of 1.3 bar [21]. Imaging parameters included a tube voltage of $60-80 \mathrm{kV}$ and a tube current of $50-450 \mathrm{~mA}$. Images were acquired at 7.5 frames/second with a range of 10-20 s, commencing at the same time as contrast injection. Interventions were performed with FOV adjusted to the investigated region using the $30 \times 40 \mathrm{~cm}$ detector with collimation. Spatial resolution is $125 \mu \mathrm{m}$.

In patients with a known severe iodinated contrast agent allergy, $\mathrm{CO} 2$ was the only contrast agent used. In patients without absolute contraindications for ICM, hybrid angiographies were performed at the discretion of the interventionalist $(n=7)$. In hybrid angiography, ICMbased images were acquired in between a mainly $\mathrm{CO} 2-$ aided intervention if image quality was insufficient and the interventionalist was not comfortable with sole $\mathrm{CO} 2$-based imaging.

Residual stenosis of $<30 \%$ of the vessel diameter after EVT by visual assessment of the performing interventionalist was set as the endpoint [2].

\section{Image Analysis}

Post-processing of the original angiographic DICOM dataset was computed on a dedicated workstation using a 
commercially available software package (syngo $\mathrm{X}$ Workplace ${ }^{\circledR}$ VD10A, iFlow ${ }^{\circledR}$, Siemens Healthcare). One reference region of interest (ROI) was placed in the artery proximal to the vascular lesion (to assess the arterial inflow; $\mathrm{ROI}_{\text {INFLOw), and a second ROI (ROI }}$ OUTFLOw) was placed distal to the vascular lesion to assess arterial outflow. All ROIs were fitted to at least $2 / 3$ of the vessel diameter. As shape and positioning of the ROIs might influence the results [14], we used circular ROIs on the preinterventional DSA, which were semiautomatically copied to the corresponding DSA following revascularization in order to ensure that shape and position of the ROIs were comparable.

Numeric density values for the time to peak (TTP), peak density value (PD) and area under the time-density curve (AUC) were computed [2, 13-18]. The following ratios were calculated pre- and post-intervention: $\mathrm{TTP}_{\text {OUTFLOW/ }}$ TTP $_{\text {INFLOW, }}$ PD OUTFLOW/PD INFLOW and $_{\text {AUC OUTFLOW/ }}$

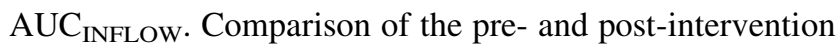
2D-perfusion parameter ratios was performed. Patient motion during an angiographic run was analyzed, based on visual impressions.

Table 1 Patient demographics and clinical parameters

\begin{tabular}{ll}
\hline Parameters & Values \\
\hline Number of patients, $\mathrm{n}$ & 9 \\
Male sex, n (\%) & $6 / 9(67 \%)$ \\
Age, years* & $65 \pm 10$ \\
Body Mass index* & $25.8 \pm 4.6$ \\
Kidney transplantation, n (\%) & $5 / 9(55 \%)$ \\
Arterial hypertension, $\mathrm{n}(\%)$ & $9 / 9(100 \%)$ \\
Diabetes mellitus, $\mathrm{n}(\%)$ & $4 / 9(44 \%)$ \\
Coronary artery disease, $\mathrm{n}(\%)$ & $6 / 9(67 \%)$ \\
Anemia, n (\%) & $7 / 9(78 \%)$ \\
Smoker, n (\%) & $2 / 9(22 \%)$ \\
Hyperthyroidism, $\mathrm{n}(\%)$ & $1 / 9(11 \%)$ \\
Contrast agent allergy, $\mathrm{n}(\%)$ & $1 / 9(11 \%)$ \\
Chronic kidney disease, $n(\%)$ & $9 / 9(100 \%)$ \\
Disease stage 4 & $7 / 9(78 \%)$ \\
Disease stage 5 & $2 / 9(22 \%)$ \\
Dialysis (with residual renal excretion) & $2 / 9(22 \%)$ \\
Peripheral arterial disease, $n(\%)$ & $9 / 9(100 \%)$ \\
Fontaine stage IIb & $8 / 9(89 \%)$ \\
Fontaine stage IV & $1 / 9(11 \%)$ \\
Pre-interventional walking distance, $\mathrm{m} *$ & $123 \pm 108$ \\
Mediasclerosis, n (\%) & $2 / 9(22 \%)$ \\
\hline
\end{tabular}

*Shown are mean values and standard deviations

\section{Statistical Analysis}

Descriptive statistical analyses of the patient demographics and angiographic data were performed. Comparisons between pre- and post-intervention data were tested using pairwise Wilcoxon signed-rank test. A $p$ value of $\leq 0.05$ was defined as statistically significant. Statistical analyses were computed using commercially available software (JMP 14, SAS Institute, JMP Office Germany, Böblingen, Germany).

\section{Results}

In total, this study included ten interventions in nine patients (six men, three women; mean age $65 \pm 10$ years), who were admitted for $\mathrm{CO} 2$-aided EVT due to clinically relevant PAD (Fontaine stage IIB (9/10) and IV (1/10)) of the pelvis $(6 / 10 ; 60 \%)$ or lower extremity $(4 / 10 ; 40 \%)$. In $7 / 9$ patients, leading indication for EVT was intermittent claudication. In total, 5/9 patients $(55 \%)$ had a previous kidney transplant. Of those, 2/9 (22\%) presented with acute

Table 2 Procedure characteristics

\begin{tabular}{ll}
\hline Parameters & Values \\
\hline Number of interventions & 10 \\
Stent, n (\%) & $9 / 10(90 \%)$ \\
Endoprosthesis, n (\%) & $1 / 10(10 \%)$ \\
Iliac artery, $n(\%)$ & $6 / 10(60 \%)$ \\
Common iliac artery & $4 / 10(40 \%)$ \\
Common and external iliac artery & $2 / 10(20 \%)$ \\
Femoral artery, $n(\%)$ & $4 / 10(40 \%)$ \\
Primary technical success, $\mathrm{n}(\%)$ & $10 / 10(100 \%)$ \\
Irradiation time, min* & $8.46 \pm 4.02$ \\
Area dose product (cGy x cm $\left.{ }^{2}\right)^{*}$ & $4274.47 \pm 4368.5$ \\
Iodinated contrast medium, $l^{*}$ & $43.2 \pm 59.73$ \\
DSA iliac artery & $52.83 \pm 76.68$ \\
DSA femoral artery & $28.75 \pm 20.97$ \\
Creatinine ( $\mu$ mol/l) & \\
Before revascularization* & $234.6 \pm 86.19$ \\
Following revascularization* & $233.11 \pm 74.51$ \\
$p$ value & $0.57 * *$ \\
Estimated glomerular filtration rate $(\mathrm{ml} / \mathrm{min})$ & \\
Before revascularization* & $24.3 \pm 7.78$ \\
48 h following revascularization* & $24.78 \pm 7.89$ \\
$p$ value & $0.63 * *$ \\
1 week following revascularization* & $25 \pm 7.29$ \\
$p$ value & $0.35 * *$ \\
\hline
\end{tabular}

*Shown are mean values and standard deviations

**Statistically not significant 
renal deterioration due to $\mathrm{PAD}$-associated perfusion changes in the transplanted kidney. All patients suffered from CKD stage $4(n=7 / 9 ; 78 \%)$ or stage $5(n=2 / 9 ; 22 \%)$. In addition to CKD, one patient $(1 / 9 ; 11 \%)$ suffered from a severe allergy to ICM and another patient $(1 / 9 ; 11 \%)$ presented with hyperthyroidism. For detailed patient characteristics, refer to Table 1.

Revascularization (nine stents, one endoprosthesis) was successfully achieved in all patients (common iliac artery $(n=6)$, superficial femoral artery $(n=4))$. In $7 / 10$ interventions, hybrid angiography was performed. In 3/10 interventions (performed in 2/9 patients), administration of additional ICM was not necessary. No patient had to be excluded due to motion artifacts. In the two patients admitted with acute transplant dysfunction, serum creatinine decreased and eGFR increased following revascularization (serum creatinine of patient 1: $406 \mu \mathrm{mol} / \mathrm{l}$ (eGFR $15 \mathrm{ml} / \mathrm{min}$ ) before and $195 \mu \mathrm{mol} / \mathrm{l}$ (eGFR $33 \mathrm{ml} / \mathrm{min}$ )

Table 3 Changes in 2Dperfusion angiography parameters following revascularization

\begin{tabular}{lllll}
\hline & Pre-intervention & Post-intervention & Difference $(\%)$ & $p$ value \\
\hline PD $_{\text {OUTFLOW }} / \mathrm{PD}_{\text {INFLOW }}$ & $0.44 \pm 0.4$ & $0.8 \pm 0.63$ & $+0.36(82 \%)$ & 0.002 \\
$\mathrm{TTP}_{\text {OUTFLOW }} / \mathrm{TTP}_{\text {INFLOW }}$ & $5.57 \pm 3.66$ & $4.25 \pm 1.64$ & $-1.32(24 \%)$ & 0.6 \\
$\mathrm{AUC}_{\text {OUTFLOW }} / \mathrm{AUC}_{\text {INFLOW }}$ & $0.34 \pm 0.22$ & $0.79 \pm 0.59$ & $+0.45(132 \%)$ & 0.002 \\
\hline
\end{tabular}

Mean values with standard deviation and percentage difference between pre- and post-revascularization TTP time to peak; PD peak density; $A U C$ area under the curve
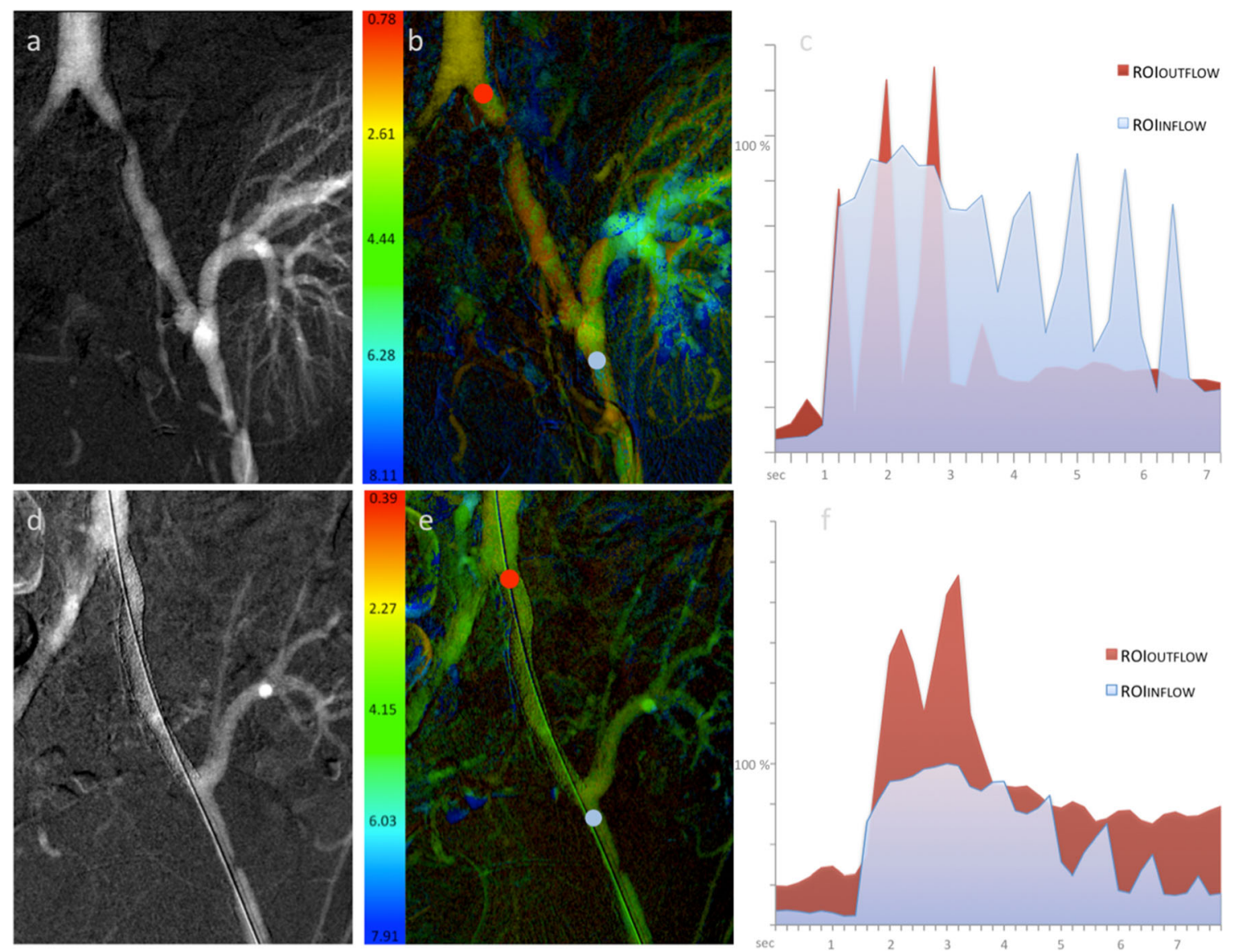

Fig. 1 Example of ROI placement and 2D-PA parameters changes following iliac endovascular therapy. Example of $\mathrm{CO}_{2}$-aided DSA and color-coded 2D-perfusion angiography image before $(\mathbf{A}, \mathbf{B})$ and after $(\mathbf{D}, \mathbf{E})$ stenting of a stenosis in the left iliac artery in a patient with kidney transplant. The $\mathrm{ROI}_{\text {INFLOw }}$ (blue) is placed in the distal

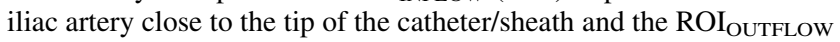

(red) is placed distant to the stenosis/stent in the proximal iliac artery. Note the increased time density values and higher area under the curve within the $\mathrm{ROI}_{\text {OUTFLOw }}$ following revascularization $(\mathbf{F})$ compared with $(\mathbf{C})$. Note that the fluctuating curves are synchronized to the arterial blood pressure 
1 week after EVT; serum creatinine of patient 2: $338 \mu \mathrm{mol} / \mathrm{l}$ (eGFR $15 \mathrm{ml} / \mathrm{min})$ pre- and $303 \mu \mathrm{mol} / \mathrm{l}(\mathrm{eGFR}$ $18 \mathrm{ml} / \mathrm{min}$ ) 1 week post-intervention) (Table 2).

2D-PA facilitated detection of blood flow changes following recanalization in all procedures. After revascularization, PD OUTFLOW $_{\text {/PD INFLOW significantly increased }}$ compared with the pre-interventional values $(0.44 \pm 0.4-0.8 \pm 0.63 ; \quad p=0.002)$. Concordantly, AUC $_{\text {OUTFLOW }} /$ AUC $_{\text {INFLOW }}$ presented significantly higher values following EVT $\quad(0.34 \pm 0.22-0.79 \pm 0.59$; $p=0.002$ ) indicating a higher amount of contrast passing through the treated lesion. A trend for a decrease in $\mathrm{TTP}_{\text {OUTFLOW}} / \mathrm{TTP}_{\text {INFLOW }}$ after the interventions was observed, but without reaching statistical significance $(5.57 \pm 3.66 \mathrm{~s}-4.25 \pm 1.64 \mathrm{~s} ; p=0.6)$. Treatment results are summarized in Table 3; an example of 2D-PA is shown in Fig. 1 for iliac EVT and in Fig. 2 for femoral EVT.

\section{Discussion}

In this study, we evaluated the feasibility of 2D-PA as a tool to monitor perfusion changes following EVT in CO2guided interventions. Angiographies during EVT in PAD have traditionally used ICM to accurately visualize the target arteries [12, 22]. However, ICM has significant associated risks, including hypersensitivity reactions, thyrotoxicosis and an increased danger of acute renal deterioration in patients with $\mathrm{CKD}$. $\mathrm{CO} 2$ has been acknowledged as a low-risk contrast agent to guide vascular interventions in patients with CKD, hyperthyroidism or hypersensitivities to ICM [1, 4, 9-11]. Nonetheless, the image quality in CO2 angiographies is unsteady $[1,12,23]$, and obtaining diagnostically valuable images in $\mathrm{CO} 2$ angiography can be more challenging than in conventional angiography [24], especially as $\mathrm{CO} 2$ angiographies are still less common compared with ICM. Generally, the assessment of blood flow and thus identification of occluded/stenotic arteries during EVT are highly subjective and operator-dependent [18]. The combination of the aforementioned difficulties in the evaluation of blood flow changes using $\mathrm{CO} 2$ might aggravate and lead to a significantly decreased diagnostic confidence.

2D-PA assigns density values to each area within an ROI and calculates mean values in each frame. These density values over time have been used to retrieve knowledge about flow rates, flow time and maximum values [2, 13-17]. In our study, we retrospectively assessed pre- and post-interventional blood flow through stenotic vessels using 2D-PA, evaluating it for possible assistance in CO2-based angiographies. As previously described, PD characterizes the maximum mean density within the ROI. The AUC is calculated from each density value at each time point using integration of successive values [2, 13-17]. The significant increases in PD OutFLow/ $_{1}$ $\mathrm{PD}_{\text {INFLOW }}$ and $\mathrm{AUC}_{\text {OUTFLOW}} / \mathrm{AUC}_{\text {INFLOW }}$ following $\mathrm{EVT}$ imply an intra-individually increased perfusion of the treated artery. $\mathrm{TTP}_{\text {OUTFLOW }} / \mathrm{TTP}_{\text {INFLOW, equaling the time }}$ from the start of the DSA run until maximum density, decreased following EVT, as expected, indicating an accelerated speed of blood flow after removal of the intravascular obstruction. We attribute the lack of significance regarding $\mathrm{TTP}_{\text {OUTFLOW }} / \mathrm{TTP}_{\text {INFLOW }}$ to the small sample size. However, despite the preliminary trendsetting results, the definition of endpoints for a successful EVT based on 2D-PA requires further evaluation with larger study populations.

This study has several limitations. The major limitation is the small number of patients admitted for EVT that received $\mathrm{CO} 2$-aided DSA before and after revascularization. Therefore, larger studies are necessary to support our findings.
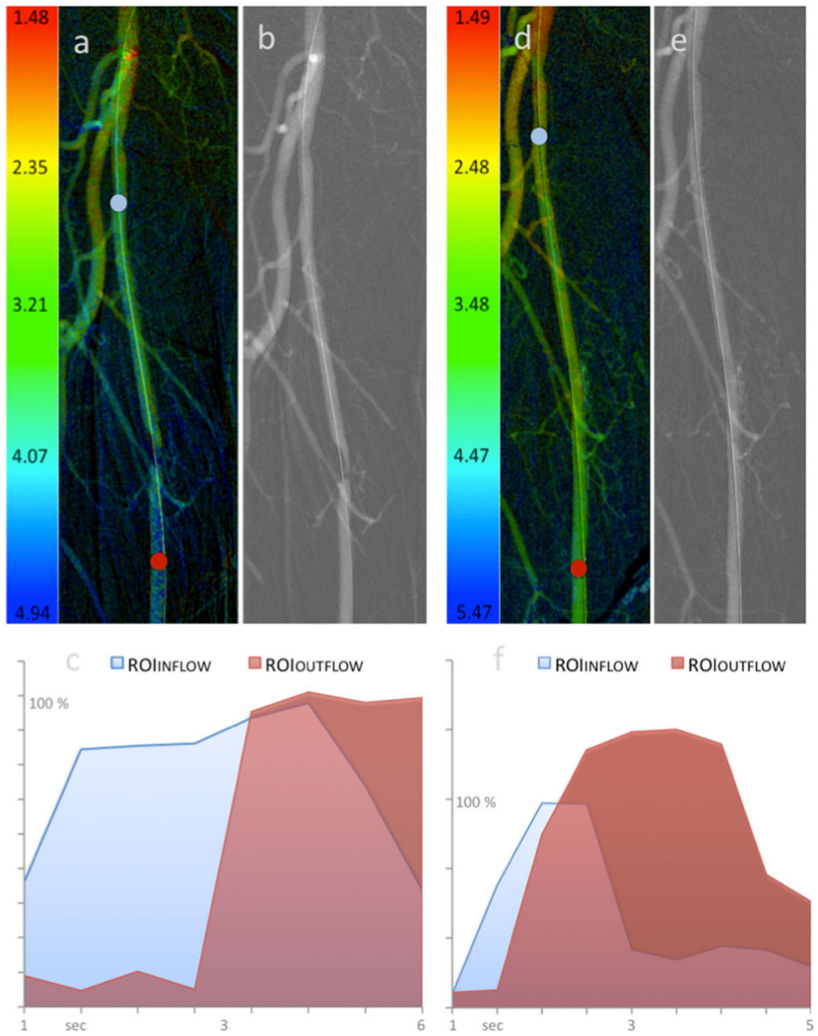

Fig. 2 Example of ROI placement and 2D-PA parameters changes following femoral endovascular therapy. Example of $\mathrm{CO}_{2}$-aided DSA and color-coded 2D-perfusion angiography image before $(\mathbf{A}, \mathbf{B})$ and after (D, E) stenting of a stenosis in the right femoral artery. The $\mathrm{ROI}_{\text {INFLOW }}$ (blue) is placed in the proximal femoral artery to assess inflow and the ROI OUTFLow (red) is placed distant to the stenosis/ stent. Note the increased time density values and higher area under the curve within the $\mathrm{ROI}_{\text {OUTFLOW }}$ following revascularization (F) compared with $(\mathbf{C})$ 


\section{Conclusion}

Evaluation of blood flow changes following EVT in CO2guided interventions using 2D-PA is feasible. This technique has the potential to objectify immediate treatment response and might result in the definition of objective, user-independent interventional endpoints.

Funding Open Access funding enabled and organized by Projekt DEAL. This study was not supported by any funding.

\section{Compliance with Ethical Standards}

Conflict of interest The authors of this manuscript declare relationships with the following companies: Siemens Healthcare and ProMedicus (Bernhard Meyer and Frank Wacker; outside the submitted work). The remaining authors declare no relationships with any companies whose products or services may be related to the subject matter of the article.

Ethical Approval All procedures performed in studies involving human participants were in accordance with the ethical standards of the institutional and/or national research committee and with the 1964 Helsinki Declaration and its later amendments or comparable ethical standards. For this type of study, formal consent is not required.

Consent for Publication For this type of study, consent for publication is not required.

Informed Consent This study has obtained IRB approval from (indicate the relevant board) and informed consent was waived.

Open Access This article is licensed under a Creative Commons Attribution 4.0 International License, which permits use, sharing, adaptation, distribution and reproduction in any medium or format, as long as you give appropriate credit to the original author(s) and the source, provide a link to the Creative Commons licence, and indicate if changes were made. The images or other third party material in this article are included in the article's Creative Commons licence, unless indicated otherwise in a credit line to the material. If material is not included in the article's Creative Commons licence and your intended use is not permitted by statutory regulation or exceeds the permitted use, you will need to obtain permission directly from the copyright holder. To view a copy of this licence, visit http://creativecommons. org/licenses/by/4.0/.

\section{References}

1. Stegemann E, Tegtmeier C, Bimpong-Buta NY, Sansone R, Uhlenbruch M, Richter A. Carbondioxide-aided angiography decreases contrast volume and preserves kidney function in peripheral vascular interventions. Angiology. 2016;67(9):875-81.

2. Hinrichs JB, Murray T, Akin M, Lee M, Brehm MU, Wilhelmi M. Evaluation of a novel 2D perfusion angiography technique independent of pump injections for assessment of interventional treatment of peripheral vascular disease. Int J Cardiovasc Imaging. 2017;33(3):295-301.

3. Krause D, Burghaus I, Thiem U, Trampisch US, Trampisch M, Klaassen-Mielke R. The risk of peripheral artery disease in older adults - seven-year results of the get ABI study. Vasa. 2016;45(5):403-10.

4. Fujihara M, Kawasaki D, Shintani Y, Fukunaga M, Nakama T, Koshida R. Endovascular therapy by $\mathrm{CO}_{2}$ angiography to prevent contrast-induced nephropathy in patients with chronic kidney disease: a prospective multicenter trial of $\mathrm{CO}_{2}$ angiography registry: EVT by $\mathrm{CO}_{2}$ angiography in CKD patients. Catheter Cardiovasc Interv. 2015;85(5):870-7.

5. Endorsed by: the European Stroke Organisation (ESO), Authors/ Task Force Members, Tendera M, Aboyans V, Bartelink M-L, Baumgartner I, ESC Guidelines on the diagnosis and treatment of peripheral artery diseases: Document covering atherosclerotic disease of extracranial carotid and vertebral, mesenteric, renal, upper and lower extremity arteries * The Task Force on the Diagnosis and Treatment of Peripheral Artery Diseases of the European Society of Cardiology (ESC). Eur Heart J 2011;32(22): 2851-906.

6. Norgren L, Hiatt WR, Dormandy JA, Nehler MR, Harris KA, Fowkes FGR. Inter-society consensus for the management of peripheral arterial disease (TASC II). J Vasc Surg. 2007;45(1): S5-67.

7. Dua A, Lee CJ. Epidemiology of peripheral arterial disease and critical limb ischemia. Tech Vasc Interv Radiol. 2016;19(2): 91-5.

8. Belch JJF. Critical issues in peripheral arterial disease detection and managementa call to action. Arch Intern Med. 2003;163(8): 884 .

9. Cho KJ. Carbon dioxide angiography: scientific principles and practice. Vasc Spec Int. 2015;31(3):67-80.

10. Miller FJ, Mineau DE, Koehler PR, Nelson JA, Luers PD, Sherry RA. Clinical intra-arterial digital subtraction imaging. Use of small volumes of iodinated contrast material or carbon dioxide. Radiology. 1983;148(1):273-8.

11. Krasny R, Hollmann J, Günther R. Erste Erfahrungen mit $\mathrm{CO}_{2}$ als gasförmiges Kontrastmittel in der DSA. RöFo - Fortschritte Auf Dem Geb Röntgenstrahlen Bildgeb Verfahr. 1987;146(04):450-4.

12. Gupta A, Dosekun AK, Kumar V. Carbon dioxide-angiography for patients with peripheral arterial disease at risk of contrastinduced nephropathy. World J Cardiol. 2020;12(2):76-90.

13. Maschke SK, Renne J, Werncke T, Olsson KM, Hoeper MM, Wacker FK. Chronic thromboembolic pulmonary hypertension: evaluation of 2D-perfusion angiography in patients who undergo balloon pulmonary angioplasty. Eur Radiol. 2017;27(10): 4264-70.

14. Dewald CLA, Meine TC, Winther HMB, Kloeckner R, Maschke SK, Kirstein MM. Chemosaturation percutaneous hepatic perfusion (CS-PHP) with melphalan: evaluation of 2D-perfusion angiography (2D-PA) for leakage detection of the venous doubleballoon catheter. Cardiovasc Intervent Radiol. 2019;42(10): 1441-8.

15. Maschke SK, Werncke T, Renne J, Kloeckner R, Marquardt S, Kirstein MM. Transjugular intrahepatic portosystemic shunt (TIPS) dysfunction: quantitative assessment of flow and perfusion changes using 2D-perfusion angiography following shunt revision. Abdom Radiol. 2018;43(10):2868-75.

16. Maschke SK, Werncke T, Klöckner R, Rodt T, Renne J, Kirstein MM. Quantification of perfusion reduction by using 2D-perfusion angiography following transarterial chemoembolization with drug-eluting beads. Abdom Radiol. 2018;43(5):1245-53.

17. Becker LS, Stahl K, Meine TC, von Falck C, Meyer BC, Dewald CLA. Non-occlusive mesenteric ischemia (NOMI): evaluation of 2D-perfusion angiography (2D-PA) for early treatment response assessment. Abdom Radiol Internet. 2020. https://doi.org/10. 1007/s00261-020-02457-y. 
18. Murray T, Rodt T, Lee MJ. Two-dimensional perfusion angiography of the foot: technical considerations and initial analysis. J Endovasc Ther. 2016;23(1):58-64.

19. Jens S, Marquering HA, Koelemay MJW, Reekers JA. Perfusion angiography of the foot in patients with critical limb ischemia: description of the technique. Cardiovasc Intervent Radiol. 2015; 38(1):201-5.

20. Reekers JA, Koelemay MJW, Marquering HA, van Bavel ET. Functional imaging of the foot with perfusion angiography in critical limb ischemia. Cardiovasc Intervent Radiol. 2016;39(2): 183-9.

21. Arendt CT, Leithner D, Lenga L, Wichmann JL, Albrecht MH, Czwikla R. Multi-observer comparison study between unenhanced quiescent-interval single-shot magnetic resonance angiography and invasive carbon dioxide angiography in patients with peripheral arterial disease and chronic renal insufficiency. Eur J Radiol. 2018;108:140-6.

22. Mehran R, Dangas GD, Weisbord SD. Contrast-associated acute kidney injury. N Engl J Med. 2019;380(22):2146-55.

23. Rolland Y, Duvauferrier R, Lucas A, Gourlay C, Morcet N, Rambeau M. Lower limb angiography: a prospective study comparing carbon dioxide with iodinated contrast material in 30 patients. Am J Roentgenol. 1998;171(2):333-7.

24. Hawkins IF, Cho KJ, Caridi JG. Carbon dioxide in angiography to reduce the risk of contrast-induced nephropathy. Radiol Clin North Am. 2009;47(5):813-25.

Publisher's Note Springer Nature remains neutral with regard to jurisdictional claims in published maps and institutional affiliations. 